\title{
СОХРАНЕНИЕ ОБРАЗНЫХ ДОМИНАНТ КАК ОДИН ИЗ КРИТЕРИЕВ ОЦЕНКИ ПЕРЕВОДА ПОЭТИЧЕСКОГО ТЕКСТА
}

В статье рассматриваются особенности художественного перевода с позиции анализа эстетических принципов автора оригинала и трактовки заложенных им смыслов. Актуальность рассмотрения системы образов оригинального произведения как элементов, порожденных индивидуальным культуроспецифичным восприятием действительности и объединяющих языковую и художественную картины мира автора, обусловлена высокой семантической емкостью поэтической формы. Цель исследования состоит в анализе воспроизведения образных доминант в переводах на русский язык знакового стихотворения крупнейшего английского поэта романтического направления У. Вордсворта «I wandered lonely as a cloud». Теоретико-методологической базой исследования послужили литературно-исторический и интегративный подходы к лингвистическому анализу текста. Материалом для практического анализа сохранения образных доминант произведения и возможности оценки успешности / адекватности переводческой интерпретации послужили пять переводов стихотворения, выполненные И. Лихачевым (1969), С. Маршаком (1969), А. Лукьяновым (2008), А. Кротковым (2006) и А. Ибрагимовым (2018). Предварительный лингвостилистический анализ стихотворения позволил выделить четыре доми- нантных образа, представленных в произведении. Проведенный анализ выявил неравнозначную интерпретации образной перспективы. Образы природы, нарциссов и душевного состояния претерпели изменения в некоторых переводах, что способствовало сокращению «длины» порождаемых ассоциативных рядов. Изменение вектора эмоционального состояния в переводе не влечет полное изменение образной рамки: она претерпевает метаморфозы на уровне субдоминантных компонентов, при этом переводческие решения носят компенсаторный характер. Проведенный анализ свидетельствуют о том что рассмотрение образной перспективы поэтического произведения позволяет преодолеть фрагментарное изучение отдельных аспектов языкового блока, формирующего его структуру. Осмысление эстетической иерархии языковых средств, манифестирующих идейно-образный замысел автора, может помочь не только не только выявить их ценностную градацию, но и оценить адекватность интерпретации оригинального произведения при переводе.

Ключевые слова: художественный перевод, поэтический перевод, образ, образная доминанта, лингвостилистический анализ, переводческая интерпретация.

T. Marchenko

\section{CONVEYANCE OF IMAGE DOMINANTS AS A CRITERION OF TARGET TEXT QUALITY ASSESSMENT IN POETIC TRANSLATION}

The article studies the peculiarities of literary translation in the light of analysis of aesthetic principles of the author of the source text and the interpretation of sense conveyed in it. The topicality of the study of the system of images presented in the source text as the elements produced by individual culture-specific vision and incorporating the linguistic and the literary visions of the world on the part of the author are preconditioned by high semantic capacity of the poetic form. The aim of the study is to analyze how image dominants are conveyed in Russian versions of an emblematic poem by a major English Romantic poet W. Wordsworth «l wandered lonely as a cloud). Literary-historical and integrative approach to the linguist analysis of the text served the theoretic and methodological basis of the study. Five Russian versions of the poem under consideration by I. Likhachev (1969), S. Marshak (1969), A. Lukyanov (2008), A. Krotkov (2006) and A. Ibragimov (2018) served the empirical material for the analysis of image dominants conveyance and the possibility of assessment as regards the adequacy of translation inter- pretation. Preliminary linguostylistic analysis of the poem revealed four dominant images. The study has shown unequal interpretation of image prospective as presented in target texts. The images of nature, daffodils and moral state have undergone some alterations resulting in reduction of the associative line length. The corrections in the emotional vector do not alter the image framework completely: it undergoes changes at the level of its components. Some translation solutions have compensation potential. The analysis have shown that the study of image prospective allows overcoming fragmentary consideration of single aspects representing the linguistic part of the text structure. Interpretation of aesthetic hierarchy of language means manifesting idea and image concept of the author can reveal the value gradation and enhance the assessment of adequacy as regards the target text.

Key words: literary translation, poetic translation, image, image dominant, linguostylistic analysis, translation interpretation. 
Знакомство с художественным произведением как и любым предметом искусства - комплексный процесс личностного развития, в основе которого несколько взаимосвязанных этапов: восприятие, эмоциональный отклик, осмысление, соотнесение с индивидуальной интерпретативной рамкой и фиксация познавательного акта как определенного опыта. Аксиоматично, что художественный перевод признается искусством, поэтому возможности применения четко разработанных нормативных критериев к его качеству в значительной мере ограничены. Исходя из предпосылок того что «перевод изначально не может быть равен оригиналу», эстетика художественного перевода опирается на категории ценности и художественности. Так, «потери и добавления неизбежны, но он должен соответствовать ему по силе и направленности эмоционального воздействия на читателя» $[15$, с. $22-23]$.

В отношении перевода малых литературных форм, на наш взгляд, актуальной является трактовка произведения как некой динамической целостности. Так, Ю. Н. Тынянов полагает, что между элементами стихотворения «нет статического знака равенства или сложения, но всегда есть динамический знак соотносительности и интеграции» $[17$, с. 9]. Утверждая необходимость осмысления формы литературного произведения как динамической, ученый видит проявление этого динамизма в конструктивном принципе: «не все факторы слова равноценны; динамическая форма образуется не соединением, не их слиянием, а их взаимодействием и, стало быть, выдвиганием одной группы факторов за счет другой», а также в ощущении формы, которая «при этом есть всегда ощущение протекания (а стало быть изменения) соотношения подчиняющего, конструктивного фрактора с факторами подчиненными" [17, с. 9] В этой борьбе и напряжении и есть жизнь искусства.

Анализ интерпретации художественного произведения при переводе не может ограничиваться тем, что, по меткому замечанию О. Вальцеля названо «низшей математикой формы»: метрика, ритм и рифма $[3$, с. 5]. Исследование тектоники и атектоники лирического стихотворения, представляющего собой некую палитру с различной акцентуацией тонов и полутонов, неизбежно приводит к выявлению художественной фрункции, реализуемой посредством взаимоотношения двух форм: выражения и содержания. В теоретической поэтике хрестоматийной является классифрикация трех групп явлений: стилистики (поэтической фронетики, метрики, тропов и регистров слов), тематики (содержание, подчиненное художественному заданию) и композиции (построение и распределение художественного материала) [11, с. 4].

Отмечая уникальность всякого художественного текста, обусловленную нечеткостью и потенциальной бесконечностью его смыслов В. А. Лукин говорит и о потенциальной бесконечности множества его трактовок: «интерпретируя художественный текст, исследователь <..> уменьшает степень неопределенности и мно- гозначности его смысловой сферы. Но полностью устранить неопределенность интерпретатор не может - это привело бы к игнорированию самой природы художественного текста» [13, с. 241]

Следовательно, в отношении художественного перевода первостепенной задачей является анализ эстетической позиции автора оригинала и истолкование заложенных им смыслов. Высокая семантическая емкость поэтической формы обусловливает актуальность рассмотрения системы образов произведения как элементов, порожденных индивидуальным культуроспецифичным восприятием действительности и инкорпорирующих языковую и художественную картины мира автора. И. В. Арнольд пишет о том, что «образ является основным средством художественного обобщения действительности», «особой формой общественного сознания» [1, с. 113]. Проблема передачи системы образов в переводе определяется не только потенциальными вариациями ввиду ориентации на другое лингвокультурное сообщество, но и условно «техническими» возможностями сохранения метрики, ритма, сильных и слабых слогов, а также различия в длине слов, которые «заставляют стих звучать по-разному» $[4$, c. 70$]$.

Рассматривая структуру поэтического текста в аспекте перевода, Ю. В. Казарин выделяет ряд макро- и микрокомпонентов. Макрокомпоненты представлены тремя блоками: культурный (поэтологическая информация), языковой и эстетический. Дальнейшую детализацию на микроуровне получает языковой блок, в состав которого входят паралингвистические компоненты (графический, ритмический, интонационный, просодический) и собственно языковые (фонетический, словообразовательный, лексический и синтаксический [12, с. 56-57]. Таким образом, комплексный анализ репрезентации поэтической картины мира в произведении направлен на выявление стилистических приемов и средств выразительности, раскрывающих индивидуально-авторский замысел. В этом ключе мы разделяем точку зрения В. С. Модестова, утверждающего, что для «художественного перевода первостепенное значение имеет не столько понимание общей стилевой направленности оригинала, сколько правильное определение относительной ценности деталей в соотнесенности с художественным целым подлинника» [15, с. 146-147]. Эстетическая иерархия и определяет большую или меньшую ценность отдельных деталей при осуществлении процесса перевода. Очевидным видится замечание о том, что «многоплановость и разноуровневый характер выражения художественных концептов обусловливает комплексный подход к интерпретации текста, так как работа с отдельными языковыми единицами (или единицами перевода) влечет потерю образности и силы эстетического воздействия» $[14$, с. 188$]$.

Наше исследование нацелено на анализ воспроизведения образных доминант в переводах на русский язык стихотворения одного из крупнейших поэтов-лириков Великобритании 
У. Вордсворта «I wandered lonely as a cloud». Teoретико-методологической базой исследования послужили литературно-исторический и интегративный подходы к лингвистическому анализу текста. Творчество У Вордсворта по сей день вызывает профессиональный интерес переводчиков. Рассматриваемое нами произведение неоднократно переводилось на русский язык. Так, существуют два перевода признанных авторов: И. Лихачева и С. Маршака, однако в различных источниках также фигурирует более восьми версий других переводчиков и поклонников творчества поэта. Для практического анализа сохранения образных доминант произведения и возможности оценки успешности / адекватности переводческой интерпретации нами были отобраны пять переводов стихотворения, выполненные И. Лихачевым (1969) [7], С. Маршаком (1969) [5], А. Лукьяновым (2008) [8], А. Кротковым (2006) [9] и А. Ибрагимовым (2018) [6].

«l wandered lonely as a cloud» (1804) является одним из титульных стихотворений английского поэта романтического направления У. Вордсворта. Во многих источниках название этого произведения указывается не по первой строке, а в варианте «The Daffodils», обозначая тем самым ключевой образ стихотворения - нарциссы. Культурная значимость произведения обусловлена целым рядом факторов. Во-первых, творчество У. Вордсворта ярко отражает эпоху романтизма (конец XVIII - начало XIX века) и представляет природу как одну из тематических и стилевых доминант. Пасторальность как опорный мотив в творчестве поэта реализует эстетическую идею жизнеутверждающего начала, просветления и самопознания. Пейзаж являет собой не только и не столько визуальную основу для художественного изображения, сколько повод для осмысления «духа, который им управляет» [20, р. 50], единства человека и природы [16, с. 132]. Анализируемое стихотворение, в котором в том числе фигурирует озеро, как и все творческое наследие поэта, ассоциируется с живописным уголком Англии - Озерным краем в графрстве Камбрия. В местечке Кокермуг и по сей день находится популярная у туристов достопримечательность Дом Вордсворта.

Заметим, что «The Daffodils» входит в обязательную школьную программу по курсу литературы и истории литературы Англии в Англии, Уэльсе и Северной Ирландии. Референции к стихотворению представлены в различных справочных и лексикографических источниках лингвистического и культуроспецифичного плана. Так, в «The Longman Dictionary of English Language and Culture» словарная статья на заглавное слово «daffodil» содержит не только описание цветка, но и пояснение его культурной значимости как символа Уэльса, а также первые четыре строки рассматриваемого нами стихотворения с пояснением, что это произведение знакомо практически всем британцам [18, р. 321]

Неизменная культурная релевантность произведения обеспечивает его преемственность и востребованность в разных сферах культуры: музыке, маркетинге, пародии, сатире и др. Так, в 2007 году в рамках рекламной кампании «Совет по Туризму Камбрии и Озёрного Края» представил рэп-обработку стихотворения в исполнении стилизованного представителя фауны региона рыжей белки MC Nuts [19]. Высокая частотность обращения к поэтическому произведению свидетельствует о его эстетической ценности как элемента культурного континуума в различных типах дискурсивных пространств.

Структурно произведение состоит из четырех строф, каждая по шесть строк. Метрически стихотворение оформлено четырехстопным ямбом с перекрестной рифмой в первых четырех строках строфы и парной в последних двух. Ритмический рисунок произведения определяет его фоносемантические свойства и с самого начала раскрывает размеренность, плавность и отсутствие суетливости во всем происходящем:

"I wandered lonely as a cloud

That floats on high o'er vales and hills,

When all at once I saw a crowd,

A host, of golden daffodils,

Beside the lake, beneath the trees,

Fluttering and dancing in the breeze» [21]

общая мелодика стихотворения задается дифтонгом [ou] в лексемах lonely, floats, o'er, host и golden. Итерация звука создает ощущение мягких движений, неторопливой походки автора прогуливающегося на природе. Аллитерация губно-зубных согласных [f] и [v] передает образ дуновения ветра, шелеста листвы и других звуков природы, актуализирующихся во всех строфах произведения. Наряду с этим, фонестема fl-, фигурирующая в нескольких лексических единицахfloats, fluttering, flash - усиливает значение неуловимости и легкости [10, с. 87-88, с. 90-92]. Синтаксис характеризуется комплексностью использованных структур: осложненные предложения и инверсированные элементы: "Continuous as the stars that shine / And twinkle on the milky way, / They...». Или, например: "Ten thousand saw / at a glance, / Tossing their heads....

Однако наибольший интерес представляет лексический уровень произведения. В стихотворении отражены разные стилистические пласты лексики: основу составляет нейтральный вокабуляр ( hill, cloud, crowd, dance, glace и др.), наряду с которым используются элементы книжного стиля, обозначающие как понятия и объекты (vale, o'er, oft), так и эмоциональную оценку или состояние (jocund, glee, sprightly, pensive, bliss)

Ключевыми стилистическими приемами являются развернутые сравнения и метафоры. Так, в первой строфе поэт сравнивает себя с природным явлением - облаком, проплывающим над долинами и холмами. Эпитет lonely поддерживает общий эмоциональный настрой уединенной прогулки. Здесь же вводится метафора живописного танца цветов (fluttering and dancing), которая получает свое развитие во второй и третьей строфах. Так, образ нарциссов представлен колористическим эпитетом golden и квантификатора- 
ми-олицетворениями a host (множество, войско) a crowd (толпа, скопление). Изобилие цветов гиперболизируется через аллюзивное сравнение с галактикой - Continuous as the stars that shine / And twinkle on the milky way, эnumem never-ending, а также конвергенцию инверсии и гиперболы: Ten thousand saw / at a glance. Оживленное движение цветов передается лексемой dance с уточняющим атрибутивом sprightly. Таким образом развернутая метафора получает развитие во второй строфе.

В третьей строфе метафора танца экстраполируется на волны: The waves beside them danced. Мы наблюдаем усиление образа оживленного движения, колыхания, которые, во многом благодаря эпитетам с положительной семантикой не вызывают чувства беспокойства или тревоги Заметим, «танец» цветов трогает поэта больше он видит в нем ликование: but they / Out-did the sparkling leaves in glee. В этой строфре также вводится идея единения с природой, которая имеет свое развитие в заключительных строках произведения: A poet could not be but gay, / In such a jocund company! Лексический повтор / gazed - and gazed - but, обособленный тире, вторит заданному ранее ритму и фокусирует внимание на ключевых образах стихотворения.

Четвертая строфа написана в настоящем времени, тем самым автор связывает опыт прошлого и определяет его неизменную значимость для текущего момента. Настроение, представленное в этом отрывке, контрастирует с предыдущими строфами, так как оно более меланхоличное и печальHoe: Ilie / In vacant or in pensive mood (vacant - беззаботный, отсутствующий, pensive - задумчивый, печальный, меланхоличный). Образ танца как проявления радости, легкости и ликования привносит в душу поэта гармонию и умиротворение.

Вслед за Н. С. Болотновой, мы полагаем, что каждая лексическая единица имеют индивидуальный потенциал и "длина» образуемых им в сознании читателя «ассоциативных линий» различна, как различно участие слова в создании образа» [2, с. 475]. Лингвостилистический анализ произведения и метод “слово-образ» позволяют выявить несколько индивидуальных художественных образов, создающих ассоциативную перспективу произведения. Так, в качестве опорных образов представляется возможным назвать:

1. Образ природы как места для уединения, получения жизненного опыта, духовного развития и переживаний.

2. Образ нарциссов как олицетворение яркости, легкости жизни, динамики, свежести эмоций гармонии

3. Образ галактики как чего-то бесконечного и недосягаемого.

4. Образ душевной гармонии и умиротворения как богатства.

Отобранные нами переводы стихотворения были проанализированы в аспекте интерпретации и воссоздания образной перспективы, заложенной автором. Наряду с этим, мы принимали во внимание стилистический регистр лексиче- ского репертуара, представленного тремя категориями: нейтральная, книжная / высокая и архаичная лексика. Заметим, что во всех переводах сохранена четырехстрофная структура (по шесть строк) и метрика оригинала.

Обратимся к переводу И. Лихачева. В первой строфре образ природы представлен иным природным явлением - печальным туманом, который реет среди гор и долин. Переводчик сохраняет прием олицетворения и рисует монументальный образ, который смягчается уже в первой строфе мы наблюдаем ветерок, шатающий цветы. Образ нарциссов вербализован таким лексемами, как стан, толпа, сто сотен. Метафора танца интродуцирована строкой И каждый трепетал цветок, и получает развитие в различных словоформах с корнем «пляс»: плясать, плясала, пляс. Мягкость образу добавляет плавность линий: цветы вились по очертанью излучины береговой.

Образ галактики представлен не только с акцентом на множественности, но и блеске, характерном для небесных светил: Бесчисленны в своем мерцанье, / Как звезды в млечности ночной. Название самой галактики заменено на свойство по значению исходного прилагательного (млечный - млечность), но узкий лингвистический контекст и наличие определения ночной, позволяют выстроить исходный ассоциативный ряд. ЦЦенность описанного опыта передана следующими строчками: Но сердиу было невдогад, / Какой мне в них открылся клад. Выбранный переводчиком глагол совершенного вида манифестирует завершенность процесса и естественность самого действия. Автор перевода сохраняет лексический регистр и использует как стилистически нейтральную, так и архаичную, книжную, экспрессивную лексику: око, реять, стан, невдогад и др.

Перевод С. Маршака открывается сравнением, в котором сохранен образ тучки. Динамика естественного движения и переживаний передана многочисленными лексемами: шел, зашелестели, бежали, качая и др. Образ нарциссов воспроизводится лексемой златооки, основа которого, как правило, используется в эпитете златоокий. Подобную номинацию в значении нарциссы характернадля высокого литературного стиля, соответственно, переводчик изменил стилистический регистр базового слова-образа. Наряду с этим, развернутая метафора танца цветов передана разными лексическими единица, стилистический прием повтора утерян: зыбкий хоровод, резвый танец, карнавал, пляшет. Образ значительного количества цветов, соизмеримого с галактикой, сохранен. При этом референция к карнавалу, предполагающему буйство красок и безудержное веселье, несколько меняет интенсивность и диспозицию настроения: в оригинале прослеживается цепочка “одиночество - радость меланхоличность - беззаботность - радость", в то время как в переводе она трансформируется: «одиночество - безудержное веселье - грусть радость».

В интерпретации А. Лукьянова единение с природой выражено уменьшительно-ласкатель- 
ной формой облачко. Настроение одиночества и уединения воссоздано лишь частично, так как семантика лексемы один: Один, меж долом и горой, амбивалента: в отсутствии кого-либо или испытывая одиночество. Образ нарциссов претерпел наиболее значительные изменения: олицетворение с толпой заменено на рой (скопление насекомых), используются глаголы, предполагающие побег (стремятся ускользнуть, мелькают) и другие перемещения: Десятки тысяч их сплелись, / Головки устремляя ввысь. Соответственно, создается впечатление несколько хаотичных, разнонаправленных движений. Метафора танца сокращена и появляется только в заключительной строчке: И сердие счастием полно, / Танцуя с ними заодно. Сравнение с галактикой также имеет противоречивую вербализацию с точки зрения ассоциативного ряда: Толпясь, как звёзды, что сверкают, / Собой украсив Млечный Путь. Так, ассоциации с толпой как временным и случайным скоплением, которое часто хаотично и сливается в единую массу, резонирует с глаголом украсить, рождающим более позитивные семантические связи. Настроение гармонии и единения с природой лексически выражено восхищением радостным парадом. Но в заключительной строфе мы наблюдаем интенсификацию настроения, крайнюю степень грусти, когда приходиться только твердо надеяться на лучшее: Когда уныл мой арустный взор, / Я вспоминаю в упованье.

В интерпретации стихотворения А. Кротковым также наблюдается замена компонентов ключевых образов. Например, метафора танца нивелирована и скопление цветов получает номинацию табунок, а небесные светила - звездный рой. Переводчик смещает фрокус на колористику, обыгрывая ее в различных номинациях: искрится блестками, златых нарциссов, но ярче золото земли, златоцвет моей души, круженье золотых цветов. Богатство вербализовано как дар, которому следует радоваться: Дарованному благу рад, / Смотрю, не отрывая взгляд. Настроение в заключительной строфе задумчивое и блаженное: Когда я в мысли ухожу, / Когда блаженствую в тиии

Аналогичную замену и изменение компонентов образной рамки можем наблюдать и в переводе
А. Ибрагимова. Лексический повтор, передающий движение нарциссов, получает разноплановое лексическое оформление: хоровод, пляска, посылали свой привет, танцует. При этом движение волн также пляска, но медлительная. Абстрактное понятие богатства и состояния конкретизируется лексемой цена и получает развитие в последующей метафроре: Тогда не знал я всей цены / Живому золоту весны. Образ галактики заменен на звездный шатер, который ассоциируется с покровом, балдахином, легкой, но объемной постройкой. Идея большого количества цветов в данном контексте элиминирована.

Необходимо отметить, что в каждом из рассмотренных нами переводов, есть примеры неординарных, ярких переводческих решений. Однако, как показывает сравнительный анализ воспроизведения образной перспективы, интерпретации не являются равнозначными. С точки зрения сохранения не только доминантных образов, но и стилистических приемов и средств их реализующих, а также лексического регистра, перевод И Лихачева наиболее близок к оригиналу. Образы природы, нарциссов и душевного состояния претерпели незначительные изменения в интерпретации С. Маршака, но некоторое сокращение “длины» ассоциаций, тем не менее не повлекло изменение в векторе эмоционального состояния, транслируемого оригинальным произведением. Переводы А. Лукьянова, А. Кроткова и А. Ибрагимова демонстрируют изменение компонентов образной рамки. При этом переводческие решения А. Лукьянова носят более последовательный характер, так как содержат меньше отступлений и большее количество компенсаторных элементов.

Анализ воспроизведения образной перспективы поэтического произведения позволяет преодолеть фрагментарное изучение отдельных аспектов языкового блока, формирующего его структуру. Осмысление эстетической иерархии языковых средств, манифестирующих идейно-образный замысел автора, может помочь не только выявить их ценностную градацию, но и оценить адекватность интерпретации оригинального произведения при переводе.

\section{Литература}

1. Арнольд И. В. Стилистика. Современный английский язык. М.: Флинта: Наука, 2002. 384 с.

2. Болотнова Н. С. Филологический анализ текста. М.: Флита-Наука, 2007. 520 с

3. Вальцель О. Сущность поэтического произведения // Проблемы литературной формы. M.: URSS: КомКнига, 2007. C.1-36.

4. Волкова Е. В. Два перевода одного стихотворения: Марина Цветаева «Маме» // Филологические науки. Вопросы теории и практики Тамбов: Грамота, 2015. №5 (47). С.68-73.

5. Вордсворт У. Златооки (перевод С. Маршака) URL: http://thelib.ru/books/marshak_samuil/perevodi_iz_angliyskih_i_ shotlandskih_poetov-read-18.html. (Дата обращения: 20.03.2019)

6. Вордсворт У. Как тучи одинокой тень (перевод А. Ибрагимова) URL: https://stihionline.ru/stihi-uilyama-vordsvorta/, (Дата обращения: 20.03.2019)

7. Вордсворт У. Печальным реял я туманом (перевод И. Лихачева) URL: http://thelib.ru/books/vordsvort_u/izbrannaya_ lirika-read-18.html. (Дата обращения: 20.03.2019).

8. Вордсворт У. Я брел, как облачко весною (перевод А. Лукьянова) URL: http://eng-poetry.ru/Poem.php?Poemld=10 (Дата обращения: 20.03.2019)

9. Вордсворт У. Я летним облачком блуждал (перевод А. Кроткова) URL: http://forum.ingenia.ru/viewtopic. php?id=18222. (Дата обращения: 20.03.2019). 
10. Воронин С. В. Основы фоносемантики. М.: ЛЕНАНД, 2006. 248 с

11. Жирмунский В.М.Композиция лирических стихотворений. Петербург: Опояз, 1921. 107 с.

12. Казарин Ю. В. Поэтический текст как система. Екатеринбург: Изд-во Урал. Ун-та, 1999. 260 с

13. Лукин В. А. Художественный текст: Основы лингвистической теории. Аналитический минимум. М.: Ось-89, 2008. $560 \mathrm{c}$.

14. Марченко Т. В. Литературный текст и интерпретационная позиция переводчика: в поисках адекватного решения // Гуманитарные и юридические исследования. 2017. №2. С.186-191.

15. Модестов В. С. Художественный перевод: история, теория, практика. М.: Издательство Литературного института им. А. М. Горького, 2006. 463 с.

16. Осташевская М. Г. Поэтическая картина мира в ранней поэзии У. Вордсворта: словарный метод исследования // Филологические науки. Вопросы теории и практики Тамбов: Грамота, 2015. №7 (49): в 2-х ч. Ч. II. С.130-133.

17. Тынянов Ю. Н. Проблема стихотворного языка. М.: КомКнига, 2010. 176 с

18. Longman Dictionary of English Language and Culture. Second edition. Barcelona: Addison Wesley Longman, 1998 $1569 p$.

19. Nuts MC URL: https://www.youtube.com/watch?v=VXbrSALG684. (Accessed: 20.03.2019)

20. Rodway A. The Growth and Nature of English Romanticism. // The Romantic Conflict. London: Chatto and Windus, 1963. P. 37-76.

21. Wordsworth W. I wandered Lonely as a cloud URL: https://www.poetryfoundation.org/poems/45521/i-wandered-lonelyas-a-cloud. (Accessed: 20.03.2019).

\section{References}

1. Arnol'd I. V. Stilistika. Sovremennyi angliiskii yazyk (Stylistics. Modern English). Moscow: Flinta: Nauka, 2002. 384 p (In Russian)

2. Bolotnova N. S. Filologicheskii analiz teksta (Philological Analysis of the Text). Moscow: Flita-Nauka, 2007. 520 p. (In Russian).

3. Val'tsel' $O$. Sushchnost' poeticheskogo proizvedeniya (The Essence of a Poetic Work) // Problemy literaturnoi formy. Moscow: URSS : KomKniga, 2007. P. 1-36. (In Russian).

4. Volkova E. V. Dva perevoda odnogo stikhotvoreniya: Marina Tsvetaeva «Mame») (Two Translations of One Poem: $M$. Tsetayeva "To Mother") // Filologicheskie nauki. Voprosy teorii i praktiki Tambov: Gramota, 2015. No.5 (47). P. 68-73. (In Russian).

5. Wordsworth W. Zlatooki (perevod S. Marshaka) (I Wandered Lonely As a Cloud (translated by S. Marshak) URL: http:// thelib.ru/books/marshak_samuil/perevodi_iz_angliyskih_i_shotlandskih_poetov-read-18.html. (Accessed: 20.03.2019). (In Russian).

6. Wordsworth W. Kak tuchi odinokoi ten' (perevod A. Ibragimova) (I Wandered Lonely As a Cloud (trans/ated by A. Ibragimov) URL:https: //stihionline.ru/stihi-uilyama-vordsvorta/. (Accessed: 20.03.2019). (In Russian)

7. Wordsworth W. Pechal'nym reyal ya tumanom (perevod I. Likhacheva) (I Wandered Lonely As a Cloud (translated by I. Likhachev) URL: http://thelib.ru/books/vordsvort_u/izbrannaya_lirika-read-18.html. (Accessed: 20.03.2019). (In Russian)

8. Wordsworth W. Ya brel, kak oblachko vesnoyu (perevod A. Luk'yanova) (I Wandered Lonely As a Cloud (translated by A. Luk'yanov) URL: http://eng-poetry.ru/Poem.php?Poemld=10. (Accessed: 20.03.2019). (In Russian).

9. Wordsworth W. Ya letnim oblachkom bluzhdal (perevod A. Krotkova) (I Wandered Lonely As a Cloud (translated by A. Krotkov) URL: http://forum.ingenia.ru/viewtopic.php?id=18222. (Accessed: 20.03.2019). (In Russian).

10. Voronin S. V. Osnovy fonosemantiki (Basics of Phonosemantics). Moscow: LENAND, 2006. 248 p. (In Russian)

11. Zhirmunskii V. M. Kompozitsiya liricheskikh stikhotvorenii (Composition of Lyrical Poems). Peterburg : Opoyaz, 1921 107 p. (In Russian)

12. Kazarin Yu. V. Poeticheskii tekst kak Sistema (Poetic Text as a System). Ekaterinburg: Izd-vo Ural. Un-ta, 1999. 260 p. (In Russian)

13. Lukin V. A. Khudozhestvennyi tekst: Osnovy lingvisticheskoi teorii. Analiticheskii minimum (Literary text. The basics of linguistic theory. Analitical minimum). Moscow: Os'-89, 2008. 560 p. (In Russian).

14. Marchenko T. V. Literaturnyi tekst i interpretatsionnaya pozitsiya perevodchika: v poiskakh adekvatnogo resheniya (Literary text and interpretative position of a translator: in search of adequate transiation) // Gumanitarnye i yuridicheskie issledovaniya. 2017. No.2. P.186-191. (In Russian).

15. Modestov V. S. Khudozhestvennyi perevod: istoriya, teoriya, praktika (Literary translation: history, theory, practice). Moscow: Izdatel'stvo Literaturnogo instituta im. A. M. Gor'kogo, 2006. 463 p. (In Russian).

16. Ostashevskaya M. G. Poeticheskaya kartina mira v rannei poezii U. Vordsvorta: slovarnyi metod issledovaniya (Poetic World Outlook in Early Works of W. Wordsworth: Dictionary Method) // Filologicheskie nauki. Voprosy teorii i praktiki Tambov: Gramota, 2015. No.7 (49): Part II. P. 130-133. (In Russian).

17. Tynyanov Yu. N. Problema stikhotvornogo yazyka (The Problem of Poetic Language). Moscow: KomKniga, 2010. 176 p. (In Russian).

18. Longman Dictionary of English Language and Culture. Second edition. Barcelona: Addison Wesley Longman, 1998 $1569 \mathrm{p}$.

19. Nuts MC. URL: https:/www.youtube.com/watch?v=VXbrSALG684. (Accessed: 20.03.2019).

20. Rodway A. The Growth and Nature of English Romanticism. // The Romantic Conflict. London: Chatto and Windus 1963. P. $37-76$

21. Wordsworth W. I wandered Lonely as a cloud. URL: https://www.poetryfoundation.org/poems/45521/i-wanderedIonely-as-a-cloud. (Accessed: 20.03.2019). 
Информация об авторе

Марченко Татьяна Владимировна - кандидат филологических наук, доцент кафедры теории и практики перевода гуманитарного института Северо-Кавказского федерального университета (Ставрополь) / tatiana-marchenko-25@ yandex.ru

\section{Information about the author}

Marchenko Tat'yana - PhD in Philology, Associate Professor, Chair of Translation Studies, Institute of Humanities, NorthCaucasus Federal University (Stavropol) / tatiana-marchenko-25@yandex.ru 